\title{
Laparoscopic Repair of Bochdalek Hernia Into Contralateral Thoracic Cavity
}

\author{
Yasoo Sugiura, MD, Keisuke Kubota, MD, PhD, Masayuki Kojima, MD, PhD, \\ Nobuhiro Nitori, MD, PhD, Etsuo Nemoto, MD, PhD, Toshinori Hashizume, MD, PhD, \\ Shizuka Kaseda, MD, PhD, Yoshiaki Sugiura, MD, PhD
}

Department of Pulmonary and Thoracic Surgery, National Hospital Organization, Kanagawa National Hospital, Hadano, Kanagawa, Japan. (Drs Yasoo Sugiura, Nemoto, Hashizume, and Kaseda); Department of Surgery, St. Luke's International Hospital, Chuou-ku, Tokyo, Japan (Dr Kubota); Department of Surgery, Hiratsuka City Hospital, Hiratsuka,

Kanagawa, Japan (Dr Kojima); Department of Gastroenterological Surgery, International University of Health and Welfare Mita Hospital, Minato-ku, Tokyo, Japan (Dr Nitori); Prevention Medical Center, Sanno Hospital and Medical Center, Minato-ku, Tokyo, Japan (Dr Yoshiaki Sugiura).

\begin{abstract}
Introduction: Bochdalek hernias in adults rarely become symptomatic. However, once the abdominal organs become incarcerated in Bochdalek hernia, surgery is required to reduce them from the thoracic cavity.

Case Description: We present the case of a 71-year-old woman with continuous chest discomfort and spontaneous epigastralgia. Computed tomography demonstrated that the colon and omentum were herniated into the right thoracic cavity through the posterior mediastinum from a left diaphragm defect. We suspected Bochdalek hernia because upper gastrointestinal series radiography showed that the esophageal hiatus was intact. At first, the hernia was unsuccessfully reduced by colonoscopy. Then laparoscopic repair was performed because the abdominal organs were herniated in the thoracic cavity opposite to the hernial orifice. We succeeded in laparoscopic repair and closure of the orifice by direct suturing and diagnosed this diaphragm hernia as Bochdalek hernia.
\end{abstract}

Discussion: Surgical repair should be performed immediately after diagnosis to prevent strangulation or perforation. To the best of our knowledge, this is the first report of adult Bochdalek hernia in which abdominal organs were herniated into the opposite side of the hernial orifice.

Key Words: Bochdalek hernia, Laparoscopy, Diaphragm hernia, Thoracic cavity.

Citation Sugiura Y, Kubota K, Kojima M, Nitori N, Nemoto E, Hashizume T, Kaseda S, Sugiura Y. Laparoscopic repair of bochdalek hernia into contralateral thoracic cavity. CRSLS e2014.00152. DOI: 10.4293/CRSLS.2014.00152.

Copyright (C) 2014 SLS This is an open-access article distributed under the terms of the Creative Commons Attribution-Noncommercial-ShareAlike 3.0 Unported license, which permits unrestricted noncommercial use, distribution, and reproduction in any medium, provided the original author and source are credited.

Address correspondence to: Yasoo Sugiura, MD, Department of Pulmonary and Thoracic Surgery, National Hospital Organization, Kanagawa National Hospital, Hadano, Kanagawa, Japan. Telephone: +81-463-81-1771, Fax: +81-463-82-1774, E-mail: yasoos@hotmail.com

\section{INTRODUCTION}

Bochdalek hernia is not as common as other hernias in adults, and surgeons cannot appropriately judge surgical indication and are hesitant to perform surgical repair because of a lack of experience with diaphragm hernia surgery in adults. Congenital hernia resulting from developmental failure of the posterolateral diaphragm foramina to fuse properly was first described in $1848 .{ }^{1}$ Bochdalek hernia usually presents during the neonatal period with respiratory symptoms and is associated with significant mortality ${ }^{2}$; however, some cases may remain asymptomatic through childhood and adulthood. ${ }^{3}$ Once the abdominal organs become incarcerated, excruciating pain occurs, as in other ventral hernias.

During the course of the present case, we learned 2 important points: (1) the optimal timing of surgical repair and (2) how to approach the repair of Bochdalek hernia. In our case, the colon and omentum were herniated into the contralateral thoracic cavity. Reviewing the literature of Japanese cases, the abdominal organs herniated into 


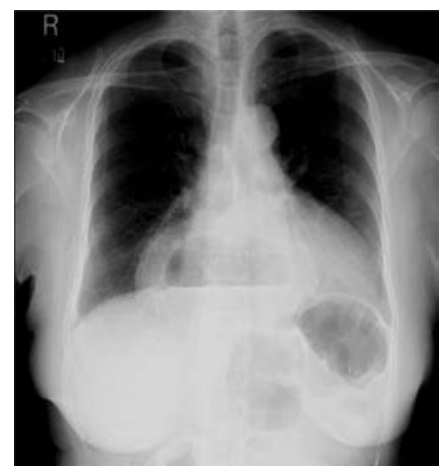

Figure 1. Chest radiography in January 2012 revealed colon gas in the mediastinum.

the thoracic cavity on the same side as the hernial orifice in all reported cases. Surgical approaches from the abdominal cavity rather than from the thoracic cavity were performed more frequently, regardless of whether the hernial orifice was on the right or left side. To the best of our knowledge, this is the first report of Bochdalek hernia in an adult in which the abdominal organs were herniated on the opposite side of the hernial orifice. This case report provides useful information for the management of symptomatic Bochdalek hernias.

\section{CASE REPORT}

A 71-year-old Japanese woman with continuous chest discomfort and intermittent epigastralgia was referred to Kanagawa National Hospital for evaluation in January 2012. Chest radiography (Figure 1) and computed tomography revealed that the colon and omentum into the posterior mediastinum were herniated through the diaphragm defect (Figures 2a and 2b). We urgently trans-

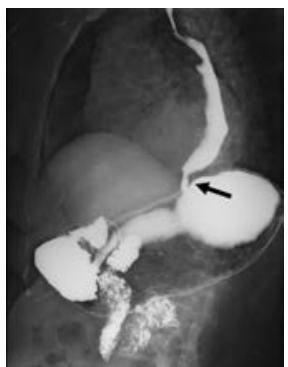

Figure 3. Upper gastrointestinal series radiography suggested the presence of not esophageal hiatal hernia but Bochdalek hernia. Arrow indicates the esophageal hiatus.

ported her to a neighboring university hospital because we diagnosed diaphragm hernia incarcerated, and rapid surgical repair was immediately required. However, she was discharged without any follow-up plan because of subsidence of symptoms. The patient returned to Kanagawa National Hospital with a report of continuous chest discomfort and intermittent back pain in late November 2012. We suspected that this diaphragm hernia was Bochdalek hernia because upper gastrointestinal series radiography revealed that the paraesophageal hernia was denied (Figure 3). Although surgical repair and closure had been scheduled, ferocious epigastralgia reappeared in December 2012. Chest radiography showed colon gas in the mediastinum, and computed tomography revealed that the transverse colon and omentum were incarcerated in the right thoracic cavity through the left diaphragm. We referred her to Mita Hospital to undergo emergent surgical repair.

At first, we did not succeed in returning the transverse colon back to the abdominal cavity by colonoscopic fiber
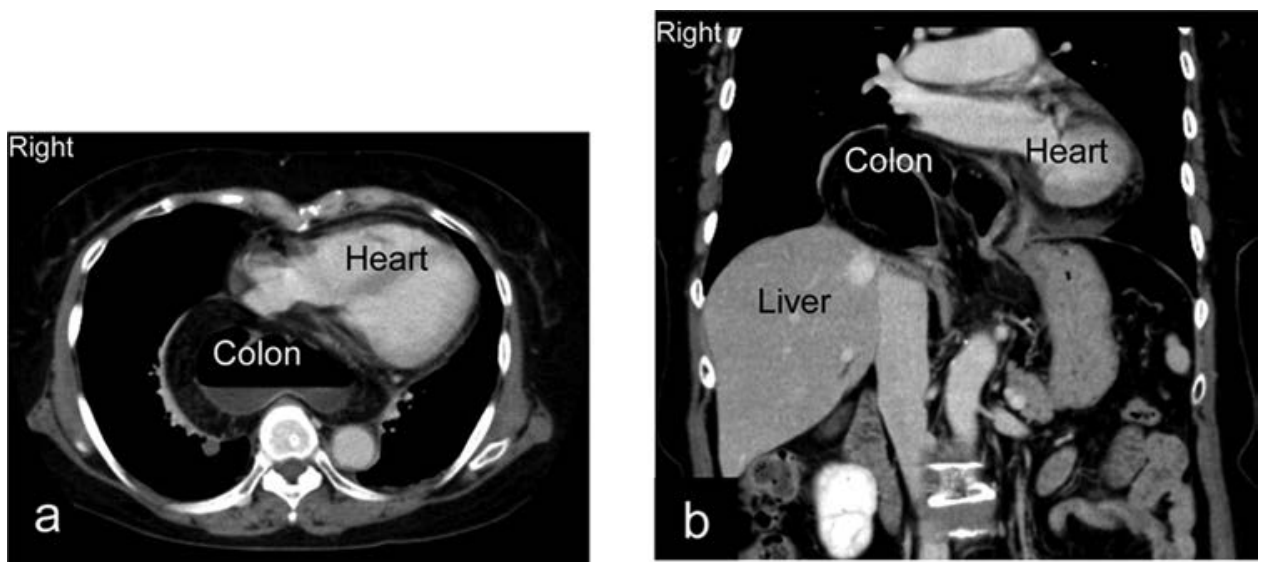

Figure 2. Axial (a) and coronal (b) computed tomographic images demonstrated that the colon and omentum were incarcerated in the right hemithorax from the left-sided diaphragm defect. 


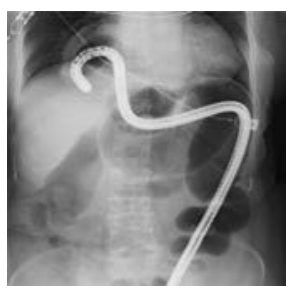

Figure 4. The colonoscope reached the transverse colon in the mediastinum, but it could not return the colon back into the abdominal cavity.

(Figure 4). Laparoscopic repair of the transverse colon and omentum and closure of the hernial orifice were performed using 5 ports. After the lateral segment of the liver was elevated, we found that the transverse colon and major omentum were incarcerated in the posterior mediastinum toward the right thoracic cavity (Figure 5a). The omentum was fixed to the circumstance of the hernial orifice. The omentum was severed, and the transverse colon was drawn back into the abdominal cavity. The hernial orifice had a smooth margin in the lumbagocostal triangle, measuring about $6 \times 5 \mathrm{~cm}$ (Figure 5b). The esophageal hiatus was intact. Therefore, we could define this diaphragm hernia as Bochdalek hernia. The hernial orifice was closed using 2-0 Prolene (Ethicon Endo-Surgery, Cincinnati, OH) with 6 sutures (Figure 5c). Surgery was completed without inserting a drain in 2 hours 33 minutes. On postoperative day 1 , the patient was able to consume food, and she was discharged on postoperative day 5. One year and 6 months later, during follow-up, there was no evidence of recurrence by chest radiography, and the patient has had no further symptoms.

\section{DISCUSSION}

Bochdalek hernia is a notorious congenital neonatal disease, which frequently causes hypoplasia of the left lung. ${ }^{2}$ In adults, Bochdalek hernias rarely become symptomatic. ${ }^{3}$ However, once the abdominal organs become incarcerated in Bochdalek hernia, surgery is required to reduce them from the thoracic cavity. Al-Emadi et $\mathrm{al}^{4}$ first reported laparoscopic repair of Bochdalek hernia in 1999. A computer-assisted search of the literature on surgical cases of Bochdalek hernia in adults in Japan was performed using Ichushi-Web (NPO Japan Medical Abstracts Society) from 1999 to May 2014. Then we analyzed the 47
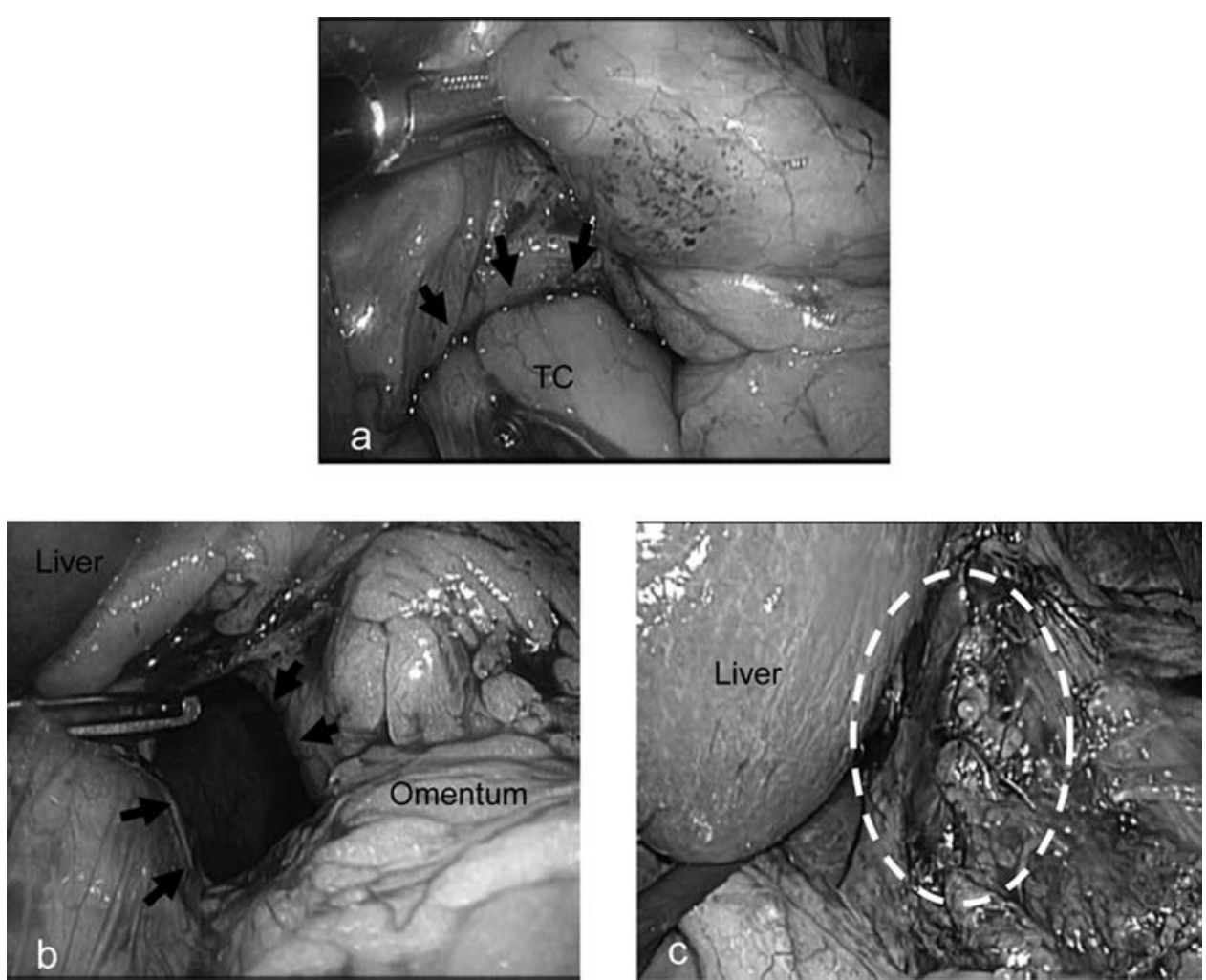

Figure 5. (a) The transverse colon (TC) and omentum were incarcerated. (b) The hernial orifice was in the lumbocostal triangle. (c) It was closed by using 2-0 Prolene. Arrows indicate the hernial orifice. The white dotted line indicates the sutured hernial orifice. 
reported surgical cases of Bochdalek hernia in adults in Japan since 1999 (Table 1).

Symptomatic Bochdalek hernia in adults should be immediately repaired, because the stomach or colon is possibly perforated in the left thoracic cavity, as observed in 6 cases. $^{5-11}$ The prognosis after surgical repair for Bochdalek hernia is excellent, with a low rate of postoperative complications in most cases.

The surgical repair approach should be selected depending on the location of the hernial orifice and abdominal organs herniated in the thoracic cavity. In the present case, the side of the colon herniation was different from that of the hernial orifice. Therefore, we decided to approach the hernia not from the hemithorax but from the abdomen. There is no report in the literature describing a case of Bochdalek hernia in adults in which the abdomi-

\section{Table 1.}

Surgical cases of Bochdalek hernia in adults.

\begin{tabular}{|c|c|c|c|}
\hline \multirow[b]{2}{*}{ Variable } & \multicolumn{2}{|c|}{ Hernial Orifice } & \multirow[b]{2}{*}{ Total } \\
\hline & Left & Right & \\
\hline Age, range (median), y & $15-80(50.5)$ & $21-85(71)$ & $15-85(51)$ \\
\hline \multicolumn{4}{|l|}{$\operatorname{Sex}^{\dagger}$} \\
\hline Female & 23 & 5 & 28 \\
\hline Male & 13 & 2 & 15 \\
\hline \multicolumn{4}{|l|}{ Approach $^{\ddagger}$} \\
\hline Thoracoscopic surgery & 3 & 0 & 3 \\
\hline Laparoscopic surgery & 9 & 1 & 10 \\
\hline Laparotomy & 19 & 6 & 25 \\
\hline $\begin{array}{l}\text { Hand-assisted } \\
\text { laparoscopic surgery }\end{array}$ & 1 & 0 & 1 \\
\hline $\begin{array}{l}\text { Thoracoscopic and } \\
\text { laparoscopic surgery }\end{array}$ & 2 & 0 & 2 \\
\hline $\begin{array}{l}\text { Thoracotomy and } \\
\text { laparotomy }\end{array}$ & 1 & 0 & 1 \\
\hline
\end{tabular}

Of the 47 surgical cases of Bochdalek hernia in adults in Japan since 1999, the hernial orifice was on the left side in 36 cases and on the right side in 7 . The median ages of patients with left- and right-sided Bochdalek hernias were 50.5 and 71 years, respectively. Endoscopic surgery was chosen in 15 cases, including 3 thoracoscopic surgical cases, 10 laparoscopic surgical cases, and 2 combined thoracoscopic and laparoscopic surgical cases.

*In 1 case, laparoscopic surgery was converted to laparotomy. ${ }^{\dagger}$ The position of hernial orifice was not described in 4 cases.

${ }^{\ddagger}$ Five cases were omitted because the position of the hernial orifice was not described in 4 cases and the approach was not described in 1 case. nal organs were herniated in the contralateral thoracic cavity. The hernial orifice was located on the left side in 36 cases and on the right in 7 . The abdominal organs herniated into the thoracic cavity on the same side as the hernial orifice in all reported cases. The median age of patients with left-sided Bochdalek hernias was 50.5 years, and that of patients with right-sided Bochdalek hernias was 71 years (Table 1), suggesting that right-sided Bochdalek hernia was more likely to occur in elderly patients. Right-sided Bochdalek hernias are comparatively rare because the right pleuroperitoneal canal closes earlier, and the liver buttresses the right diaphragm. ${ }^{12}$

Endoscopic surgery was selected for 15 cases, which included 3 thoracoscopic surgical cases, 10 laparoscopic surgical cases, and 2 thoracoscopic and laparoscopic combined surgical cases. In a case, laparoscopic surgery was converted to laparotomy. Therefore, in 14 of 15 cases, endoscopic surgery for Bochdalek hernia in adults in Japan was achieved. In these cases, relapse of Bochdalek hernia was never observed. However, there is a possibility that only successful cases were reported. It is unclear whether the predominance of surgical diaphragm repairs are approached from the abdomen or thorax; however, in most reports, approaches from the abdominal cavity were performed more frequently than from the thorax, regardless of whether the hernial orifice was on the right or left side, although the liver might present an obstacle to surgery if the hernial orifice is on the right side (Table 1). This tendency might suggest a publication bias, because almost all cases were reported by gastroenterological surgeons. Comparing our experiences with worldwide reports, Brown et $\mathrm{al}^{13}$ reviewed 124 articles comprising $173 \mathrm{pa}-$ tients. They demonstrated that minimally invasive surgical techniques have gained popularity, and laparotomy is the most widely used surgical approach. Furthermore, they concluded that using modern surgical techniques, including laparoscopy, repair can be performed safely, with short hospital stays and with minimal morbidity and mortality. Table 1 in our case study also showed that the approach from the abdominal cavity rather than from the thoracic cavity was chosen more frequently; this was in accordance with world experience. Endoscopic surgery was performed in 15 of 47 cases, and these procedures were accomplished safely in 14 of 15 cases, without any complications.

To date, there is no report of successful colonoscopic repair of Bochdalek hernia, because although this approach might enable surgeons to draw the abdominal organs from the thoracic cavity, it cannot be used to close the hernial orifice. Nonetheless, this approach presents an 
additional option for surgical repair in patients with no tolerance for general anesthesia, such as the elderly.

\section{CONCLUSIONS}

The prognosis after surgery for Bochdalek hernia repair is excellent in most patients. In contrast, the stomach or colon was ruptured in thoracic cavity in several patients. Hence, surgical repair should not be delayed for symptomatic Bochdalek hernia. To the best of our knowledge, this is the first report of Bochdalek hernia in an adult in which the abdominal organs were herniated in the opposite side of the hernial orifice.

\section{References:}

1. Salacin S, Alper B, Cekin N, Gulmen MK. Bochdalek hernia in adulthood: a review and an autopsy case report. J Forensic Sci. 1994;39:1112-1116.

2. DiFiore JW, Fauza DO, Slavin R, Wilson JM. Experimental fetal tracheal ligation and congenital diaphragmatic hernia: a pulmonary vascular morphometric analysis. J Pediatr Surg. 1995;30:917-923.

3. Mullins ME, Stein J, Saini SS, Mueller PR. Prevalence of incidental Bochdalek's hernia in a large adult population. AJR Am J Roentgenol. 2001;177:363-366.

4. Al-Emadi M, Helmy I, Nada MA, Al-Jaber H. Laparoscopic repair of Bochdalek hernia in an adult. Surg Laparosc Endosc Percutan Tech. 1999;9:423-425.

5. Yoshida H, Edazawa H, Yano K, Kamada T, Katoh H. An adult case of Bochdalek hernia with complete rupture of the colon. J Japan Surg Assoc. 2001;62:929-933.
6. Hattori M, Tamauchi T, Kuze S, Suzuki H. A case of adult Bochdalek's hernia causing gastric perforation in the thoracic cavity. J Japan Surg Assoc. 2006;67:1537-1540.

7. Matutani Y, Manaka D, Hirata Y, Shimizu M, Uehara M. A case of adult Bochdalek's hernia with intrapleural perforation of the colon. Rinsho Geka. 2008;63:1009-1013.

8. Ashikawa K, Katayama M, Kamio K, Asano T, Komoriyama H. A case of adult Bochdalek hernia causing small intestinal perforation in the thoracic cavity. Jpn J Gastroenterol Surg. 2010;43:10541058.

9. Suwa H, Nagahori Y, Takahashi T, et al. A case report of a Bochdalek's hernia in an adult with gastric perforation. Jpn J Gastroenterol Surg. 2010;43:1212-1217.

10. Kodama H, Ota H, Tsukayama S, Kawakami K, Fujioka S, Kawaura Y. A case of adult Bochdalek hernia with intrathoracic gastric perforation. J Japan Surg Assoc. 2013;74:52-56.

11. Kubota K, Yamaguchi H, Kawahara M, Kaminishi M. Bochdalek hernia in a young adult: report of a case. Surg Today. 2001;31:322-324.

12. Kanazawa A, Yoshioka Y, Inoi O, Murase J, Kinoshita H. Acute respiratory failure caused by an incarcerated right-sided adult Bochdalek hernia: report of a case. Surg Today. 2002; 32:812-815.

13. Brown SR, Horton JD, Trivette E, Hofmann LJ, Johnson JM. Bochdalek hernia in the adult: demographics, presentation, and surgical management. Hernia. 2011;15:23-30. 